\title{
Powder-bed additive manufacturing for aerospace application: Techniques, metallic and metal/ceramic composite materials and trends
}

\author{
Alexander Katz-Demyanetz ${ }^{1}$, Vladimir V. Popov Jr. ${ }^{1,}$, Aleksey Kovalevsky ${ }^{1}$, Daniel Safranchik ${ }^{1}$, and \\ Andrey Koptyug ${ }^{2}$ \\ ${ }^{1}$ Israel Institute of Metals, Technion R\&D Foundation, Technion City, Haifa 3200003, Israel \\ 2 Sports Tech Research Centre, Mid Sweden University, Östersund, Sweden
}

Received: 29 January 2019 / Accepted: 22 February 2019

\begin{abstract}
The current paper is devoted to classification of powder-bed additive manufacturing (PB-AM) techniques and description of specific features, advantages and limitation of different PB-AM techniques in aerospace applications. The common principle of "powder-bed" means that the used feedstock material is a powder, which forms "bed-like" platform of homogeneous layer that is fused according to cross-section of the manufactured object. After that, a new powder layer is distributed with the same thickness and the "printing" process continues. This approach is used in selective laser sintering/melting process, electron beam melting, and binder jetting printing. Additionally, relevant issues related to powder raw materials (metals, ceramics, multimaterial composites, etc.) and their impact on the properties of as-manufactured components are discussed. Special attention is paid to discussion on additive manufacturing (AM) of aerospace critical parts made of Titanium alloys, Nickel-based superalloys, metal matrix composites (MMCs), ceramic matrix composites (CMCs) and high entropy alloys. Additional discussion is related to the quality control of the PB-AM materials, and to the prospects of new approaches in material development for PB-AM aiming at aerospace applications.
\end{abstract}

Keywords: additive manufacturing / aerospace materials / powder-bed / high entropy alloys / titanium alloys / superalloys

\section{Introduction}

The powder-bed additive manufacturing (PB-AM) unifies several 3D-printing powder-based techniques: selective laser sintering/melting (SLS/SLM), electron beam melting $(\mathrm{EBM})$ and binder jetting printing (BJP). PB-AM is widely used in critical applications like biomedical implants [1,2], automotive [3], and aerospace [3,4].

PB-AM with the high power beams is used for different group of materials: from light metals like Aluminum [5,6] and Titanium alloys [7-10], to steels [5,11-13], and even refractory Tungsten [14], Tantalum [15], Inconel [16-21], high entropy alloys (HEAs) [22-29] and bulk metallic glass (BMG) materials [30-31]. In special literature, the term "additive manufacturing", in relation to both metallic materials and polymers, is more common than 3D-printing commonly used in the news popular literature. Out of many

\footnotetext{
* e-mail: vvp@technion.ac.il
}

AM methods, only few can be regarded as "printing" and "additive" stresses the difference with more common "subtractive" manufacturing methods. Freedom of shapes achievable in a single manufacturing process, energy and material savings and faster design-to-production times are among most prominent advantages of all AM methods including its powder-bed versions. These advantages provide the "buy-to-fly ratio" for PB-AM components close to $1: 1$

The current review aims to present the state-of-the-art in materials used in PB-AM specifically for aerospace application.

\section{Powder-bed additive manufacturing}

As stressed by the name, PB-AM uses powders as a precursor material. In beam-based PB-AM machines, thin layers of powder are deposited and leveled by dedicated mechanical systems and selectively melted by high power 
beam (laser or electron one) in the places where solid metal should occur. This process is consecutively repeated forming desired components layer-by-layer. The process is carried out either in inert atmosphere (SLM) or under vacuum $(\mathrm{EBM})$ to prevent material and component oxidation [32-36]. Unlike other traditional ways of metal processing, only a small amount of material is melting around the beam position resulting in very high heating and cooling rates. These unique processing conditions define the microstructure of the material resulting from $\mathrm{PB}-\mathrm{AM}$, and in few cases, materials can acquire unique properties (e.g. HEA and BMG).

In general, laser-based machines dominate the PB-AM equipment market in numbers and variations. One of the largest competitive advantages of the laser-based PB-AM systems over EBM is in significant number of industrially available metallic materials. So far, a single EBM machine manufacturer, ARCAM EBM [32] (now part of the GE) is holding majority of the key patents preventing other equipment manufacturers to provide competitive alternatives. Unfortunately, so far ARCAM EBM supports only few materials for industrial manufacturing (Ti64, Ti grade 2, CoCr ASTM F75 and Inconel 718).

PB-AM systems are commonly using pre-alloyed powders with the powder grains close to spherical shape allowing good definition of deployed powder layers. Laserbased PB-AM systems are commonly using rather fine precursor powders with the grain size starting from few microns, but most common are the powders the grains up to 60-80 micron. Electron beam melting PB-AM uses coarser powders with the grain size distributions commonly between 75 and 150 micron. Correspondingly, laser-based PB-AM machines use thinner powder-bed layers as compared to EBM and allow for some better spatial resolution in manufactured components (strongly defined by the powder grain size and layer thickness). Correspondingly, EBM with some thicker layers and higher achievable energy in the beam can provide higher production rates. Thus commonly for the manufacturing of smaller components with finer structure details the choice is with laser-based methods, and with larger components and higher throughput- with EBM.

Traditionally, PB-AM methods are using gas- or plasma atomized powders $[7,37]$ made from pre-alloyed material. But in cases when non-equilibrium material microstructure is desirable (like with BMG, HEA and some other materials), blends of elemental powders can be used [28,30,31,38-40].

A common feature of $\mathrm{PB}-\mathrm{AM}$ techniques is the need to use special supports to keep the part under construction from thermal deformations. Because newly manufactured hot material coexists with the loose or slightly semisintered powder having relatively low heat conductivity possible shape distortions can occur. Thus, manufacturing is always initiated from so-called start platform (commonly a relatively thick stainless steel plate) providing a good heat sink. Also, thin support structures (scaffolds) are used under all overhanging component elements. In many cases, especially when used materials are easily welding with stainless steel, support structures are also placed between the component and the start plate. These supports are removed after component is taken out from the machine after manufacturing.
Generation and placement of supports is essential part of the design file preparation for AM. Corresponding software for automatic support generation is available from the machine manufacturers and independent vendors. But proper support placement depends on the designer skills balancing minimization of material waste (minimum supports, as they are removed and cannot be returned into the process as unused powder) and component shape integrity (increasing support number preventing first layer delamination and heat deformations).

In the majority of cases, components produced in PBAM will need certain post-processing. Here three aspects related to as-manufactured state of the PB-AM components should be kept in mind: component surface roughness; different thermal history of the different parts of the component; possible residual stress in the material and presence of the supports. Because molten metal in PB$\mathrm{AM}$ is directly neighboring loose or slightly sintered powder, component outer surfaces will have certain roughness, with average values commonly determined by the dimensions of the used powder grains, partially fused with the outer surfaces $[41,42]$.

The components manufactured using PB-AM systems keeping the working area at highly elevated temperatures commonly have rather small residual stress. Such situation is true with EBM and with only some of the laser-based systems. But in most laser-based systems without additional preheating, where cooling of material behind the beam spot is happening very fast down to relatively low temperatures of the component, residual stress may present a serious problem. Thus post-processing (most commonly hot isostatic pressing) is performed [43]. Also, in all cases when component manufacturing time is significant, lower (first) and upper (last) material layers are having very different thermal history and thus may result in a different microstructure. Thus, in all cases when the microstructure of as manufactured parts is undesirable because of non-stationary heating-cooling process, or nonuniform due to the different thermal history, additional post-processing is advised.

Removing of the support structures is so far not well automated, and in many cases demands manual operations. Also, when removed, supports commonly leave relatively rough areas on the component surfaces. Excess surface roughness and remaining support structures can be treated using different chemical and electrochemical methods [44,45]. But most complicated is removal of the support structures placed in the inner channels inside the components, but industrial methods for removal of the support structures in "hard to get" spaces are start to emerge [46].

It should be noted that, despite wide commercialization of PB-AM equipment, industrial application of such methods demands special attention. Firstly, all elements of the manufacturing chain (materials, equipment, metrology, quality control, safety, life cycle analysis etc.) differ from what is well established with other methods of manufacturing of metallic components. AM systems are complex and include equipment for: sifting and mixing powders; loading and unloading the machine; post-processing; filtration and cooling; powder storage; generating and feeding inert gases; etc. 


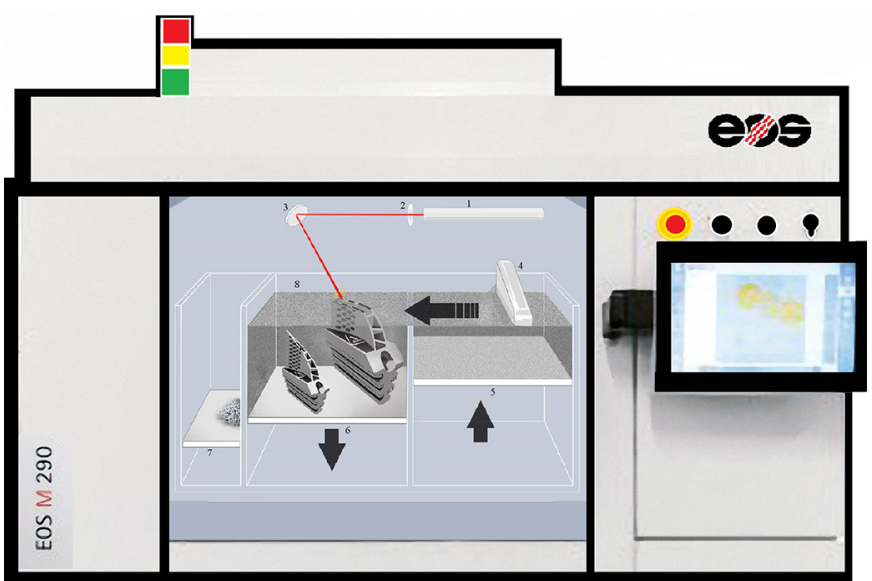

Fig. 1. Selective maser melting process: 1: laser; 2: lenses; 3: $x-y-$ scanning-mirror; 4: rake; 5 : powder supply table; 6 : build table; 7 : table for rest powder; 8 : powder-bed.

Because running such systems demands certain knowledge of operators, and especially because of the specifics of "designing for AM", many businesses are opting to design components together with the specialists and order component manufacturing from the trusted companies specializing in AM manufacturing.

Non-beam-based PB-AM technologies are also developing becoming especially competitive in the case of manufacturing non-metallic materials (ceramic, ceramicbased, composite). Binder jetting printing (BJP) is a good example of such PB-AM industrially applied technique.

\subsection{Selective laser melting}

SLM was the first powder-bed-based technique enabling to "print" metallic alloys. Nowadays, there are multiple producers of SLM machines that use different terminology (trade names) for almost the same SLM process. For example, EOS calls there process direct metal laser sintering (DMLS); Renishaw-metal powder-bed fusion (MPBF); Concept Laser-LaserCUSING ${ }^{\circledR}$; etc. [35].

Figure 1 schematically illustrates the SLM-process, where powder layer is deposited using so-called rake system "brushing the powder in" layer-after-layer with the most common layer thickness for light metals of 30-60 microns. Some of the systems use inert gas atmosphere (nitrogen or argon), some other work in mild vacuum. Ytterbium fiber laser systems usually applied to sinter metallic alloy powder in modern SLM systems.

In general, in manufacturing of complex parts, laser power control is extremely desirable, but it is not easy to implement. The higher is the laser power, the faster is melting and shorter lead time. Today, some equipment manufacturers commercialize the system with multiple lasers allowing speeding up manufacturing process. But in all PB-AM including both laser and e-beam- based ones layer processing time cannot be reduced indefinitely, certain amount of beam power delivered per surface area is always needed to avoid excessive porosity and lack of fusion defects in the resulting component. Increasing beam power also increases the dimensions of the melt pool thus reducing the ability to generate parts with very small geometric features. Thus in the cases demanding highest spatial resolution in the component shape, the beam energy should be lowered, inevitably resulting in longer component processing times [35].

Thus SLM process is beneficial for manufacturing of components with small accurate features, with the elements less than 300 microns; internal channels; lattices and similar lightweight structures; honeycomb structures and complex heat exchanger structures [47]. The physical and mechanical properties of SLM-manufactured parts could be controlled and optimized by process parameters development [48-50] and also by thermal post-processing.

\subsection{Electron beam melting}

Melting of metallic materials by electron beam was quite common for electron beam welding (EBW), well-known process for Titanium alloys, steels and some other metals. But, merging high power of the beam with its precision control resulted in a new manufacturing method: electron beam melting (EBM, or SEBM - selective electron beam melting). Corresponding beam energy up to tens of kilowatts in the beam and very small beam reflection from metallic powders give EBM certain advantages over laserbased PB-AM methods. Process is carried out in high vacuum (down to $10^{-5}$ bar) with powder layer semisintering and preheating resulting in elevated process temperatures (about half of the melting temperatures of used material) (see Fig. 2). Layer preheating before melting in vacuum provides additional powder surface degasification and desorption, and prevents powder and component oxidation. Higher available beam energies allow using powders with the grain size distribution of about 75-150 micron, and corresponding layer thicknesses of 50 to 200 micron $[51,52]$. This can provide faster layer processing times as compared to the ones common for laserbased PB-AM machines, but leads to correspondingly lower spatial resolution in component shape details, and higher component surface roughness. Preheating during whole manufacturing process leads to significantly lower internal stresses in as-manufactured components, and in some cases much better mechanical properties as compared for with traditionally manufactured alloys [32]. High power of the beam and vacuum conditions are also quite favorable for manufacturing materials with the microstructure preserving metastable states (HEA, BMG).

Semi-sintering of the powder is a feature significantly differing EBM from the laser-based PB-AM methods. This stage is necessary due to the fact that high power electron beam hitting the loose powder causes its charging. As a result, powder rises up in vacuum chamber forming a cloud (event known as "smoke"), which is stopping the process and can damage the machine. Thus, pre-sintering and preheating of the deposited loose powder layer is carried out with successively increasing beam current. Semisintering of the powder has both positive and negative consequences. Comparing to laser-based PB-AM, inside 


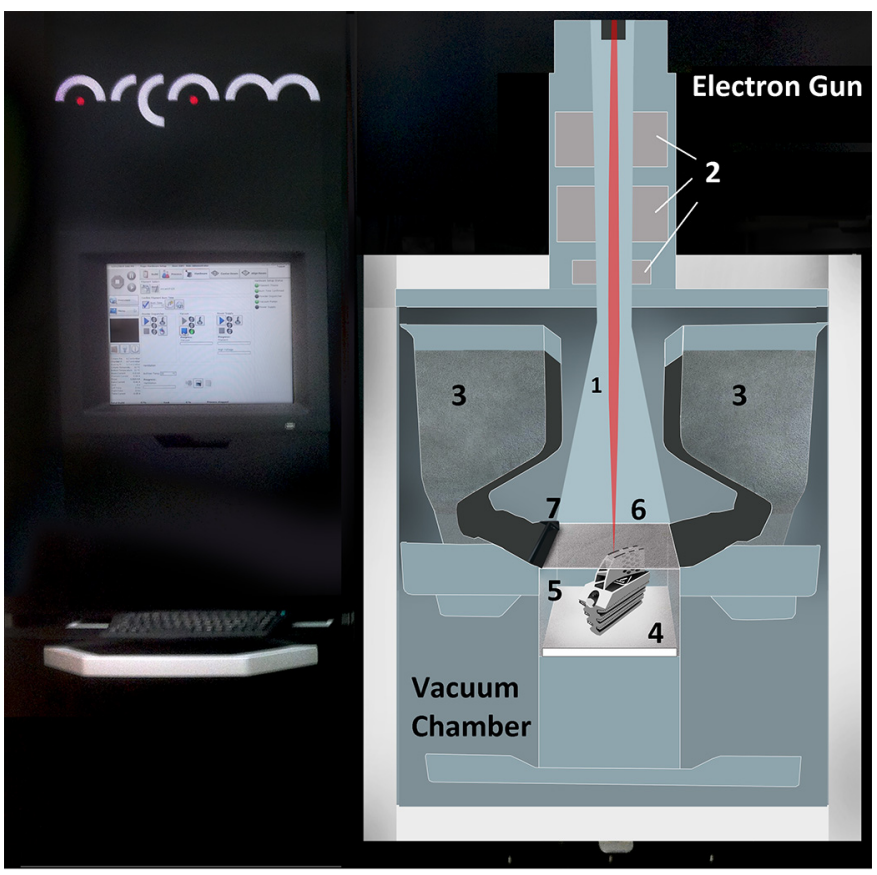

Fig. 2. Electron beam melting process: 1: electron beam; 2: electron beam control; 3 : powder containers; 4: build platform; 5 : build tank; 6: working area; 7: rake.

semi-sintered powder it is easier to stack multiple separate components in the build volume increasing component yield "per build", and makes lower demands to the number of support structures. On the other hand, a powder from the crevices, from inside the cooling channels and lattice structures can be simply shaken out. And, removing powder from such structures after EBM is significantly more complicated.

\subsection{Binder jetting printing}

The high temperature PB-AM allowed produce metallic parts, as well as MMCs which are, as known, contain some amount of ceramic phase dispersed in metallic matrix $[36,53]$. Manufacturing of high quality ceramic parts by this technique is still challenging and certain efforts are needed for its wide industrial acceptance. Thus another approach, at which melting does not occur at the first manufacturing stage, is used for PB-AM of ceramic parts. This PB-AM technique is called binder jetting printing (BJP). It uses particles bonding (binding) occurring throughout layer-bylayer building of a "green" (non-dense) part from a raw ceramic powder (see Fig. 3). Then, the manufactured "green" is subjected to post-processing (binder removal at high temperature and material's sintering) to obtain the final dense part.

BJP is a process, in which a binder is deposited onto a powder-bed to form part cross sections (see Fig. 3) [54]. This concept can be contrasted with traditional metal PB$\mathrm{AM}$, at which high intensity beam (laser or electron one) melts powder particles to form a consecutive solid material

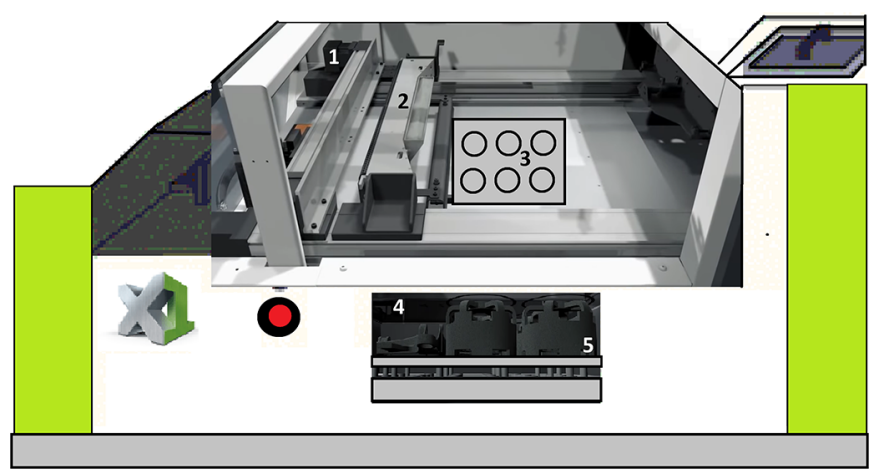

Fig. 3. Binder jetting printing process: 1 : binder jetting head; 2 : rake and powder delivery system; 3 : working area; 4 : build tank; 5 : build platform.

layers. A wide range of polymer, composite, metallic, and ceramic material processing was demonstrated, but only a few of them are commercially available. BJP production technology uses various granular/powder materials (sand, ceramic powders, metallic alloys). The printing stage requires a low heating $\left(200^{\circ} \mathrm{C}\right)$. At the sintering step, highquality and uniform heating is normally achieved. This factor leads to significant reduction in residual stresses compared with the beam-based methods of PB-AM. $[17,55]$. As is reported in the recent literature, use of BJP technology permitted to many researchers successful printing of different types of alloys, including superalloys and ceramic matrix composites (CMCs) using BJP process $[18,19,56-59]$.

\section{Materials}

Aerospace applications demand materials with certain critical properties, like high strength to weight ratio, high temperature operation. Aerospace application that demands cutting edge technologies is becoming one of the primary beneficiaries of AM. In particular, PB-AM already allows for manufacturing components with complex shapes from light metals with high mechanical strength like Titanium alloys and refractory materials like Ni-based superalloys provide quite promising manufacturing pathways. Possibility of extremely fast localized melting and cooling in PB-AM also allows for manufacturing multiple new material families with unique properties preserving a non-equilibrium states in their microstructure. Among such materials one should specifically mention high entropy and amorphous alloys. For example, amorphous or glassy alloys commonly called bulk metallic glasses (BMGs) are promising a breakthrough in the applications capable of utilizing their unprecedented resilience.

\subsection{Titanium alloys}

Titanium alloys provide a unique combination of physical and mechanical properties like small weight, high strength (high "strength to weight ratio"), good corrosion and fatigue resistance. Unlike carbon-based composites [60], 
aluminum [6] and magnesium-the Ti alloys can withstand high serving temperatures (for example aluminum usually serves up to $200^{\circ} \mathrm{C}$ ). Excellent corrosion resistance is another factor making $\mathrm{Ti}$ alloys quite useful for aerospace applications.

One of the most popular Ti alloys is $\mathrm{Ti}-6 \mathrm{Al}-4 \mathrm{~V}$, finding its place both in aerospace [61] and medical applications $[1,2]$. Up to now it is the most popular material used in AM. The weight percentage of titanium in large commercial aircrafts varies between $\sim 7 \%$ in the airframe and $\sim 36 \%$ in the gas turbine engines. Titanium is used as fatigue crack growth "stopper" in aircraft fuselage made from aluminum and also for hydraulic system pipes. Primary components of aircraft landing gear are also manufactured from forged Ti alloys. Also other structural parts like the frames of cockpit windows, kitchen and toilet parts, various fixation elements and brackets are manufactured from pure Titanium or Titanium alloys [61].

Another important property is the compatibility between $\mathrm{Ti}$ and $\mathrm{C}$-fiber reinforced polymer (CFRP), the matching between their thermal expansion coefficient and the galvanic corrosion resistance between them make the Ti alloys very attractive for composite structures [61,62].

Though applications of Ti alloys in civil aviation are quite significant, these alloys are even more widely used in military aircrafts, helicopters and space applications due to the need of high performance and unique properties, especially weight reduction.

Post treatment is sometimes required for structural parts in order to enhance their mechanical properties. Heat treatment, coatings and surface modifications are being applied to titanium structures, according to their specific use. The most used post-processing procedure for titanium parts is hot isostatic pressing (HIP), which decreases the residual porosity and improves material microstructure resulting in improved fatigue stability [43].

Beneficial properties of Titanium alloys for aerospace to large extent defined these alloys to be one of the primary targets for PB-AM material development. In PB-AM of Titanium alloys the phase formation and mechanical properties can be controlled by process parameters optimization $[7,8,10,63]$. Additive manufacturing of Tialloys has significant advantages comparing to traditional manufacturing, because of low castability and challenging machining of these alloys.

In some of the aerospace applications, like turbine blades, the resistance to fatigue is quite critical, thus improvement of as-manufactured by PB-AM component surfaces is necessary (mostly the reduction of roughness). As mentioned above, PB-AM results in a poor (rough) surfaces, so different post processing technologies are available and are continuously developed. Most of the surface treatment methods are multi-step processes that include the use of abrasive media (physical treatment) and chemical and electrochemical polishing. These methods are also combined with traditional machining, whenever needed.

\subsection{Ni-based superalloys}

In recent years, research interest in production Ni-based alloys in significantly increased, especially targeting the applications for the applications demanding high temperature low fatigue, common in aviation and aerospace industries [64-69]. In general, the term "superalloy" refers to metals that have been developed to withstand high temperatures without deforming or corroding. These alloys often combine such important parameters as outstanding yield and fatigue strength, surface stability and resistance to creep and thermal creep deformation [70-73]. Nickelbased alloys are most commonly used in various applications related to the aviation and aerospace industries, though certain applications in chemical industry demanding high corrosion stability in aggressive media at high temperatures can be found. The most recommended and currently known Ni-based superalloys used in mechanical engineering are so-called Inconel 718 and Inconel 625 .

Among beneficial properties of Inconel $718(\mathrm{Ni}-\mathrm{Cr}-$ based alloy) are corrosion resistance; fatigue, creep, and rupture strength; high working temperature (up to $980^{\circ} \mathrm{C}$ ); with tensile strength up to $1400 \mathrm{MPa}$ and $21 \%$ elongation at room temperature $[18,74]$. Hardening of the alloy is achieved due to the slow release of the intermetallic compounds of $\mathrm{Ni}$ with $\mathrm{Ti}$ and $\mathrm{Nb}[17,21,75]$. Inconel's weldability and post-weld behavior (resistance to cracking) are also superior [76]. Unique combination of mechanical and physical properties of this Ni-based alloy resulted in a wide range of applications, including aerospace. Typical examples of components produced from Inconel 718 are components for liquid fuel rockets, fasteners, casings, instrumentation parts, and for aircraft and land-based gas turbine engines [73,77].

Inconel 625, another Ni-Cr-based alloy, is used for its high strength, excellent manufacturability (including joining), and outstanding corrosion resistance. Service temperatures range from cryogenic to $982^{\circ} \mathrm{C}[74,78,79]$. Strength of Inconel 625 is resulting from the stiffening effect of $\mathrm{Mo}$ and $\mathrm{Nb}$ on its $\mathrm{Ni}-\mathrm{Cr}$-matrix; thus precipitation-hardening treatment is not required. This combination of elements also is responsible for superior resistance to a wide range of corrosion mechanisms and ability to work in strongly aggressive environment, as well as to the resistance to high-temperature oxidation and carburization. High tensile, creep, and rupture strength, outstanding fatigue and thermal-fatigue strength; oxidation resistance; and excellent weldability and brazeability are the properties that make Inconel 625 advantageous for the aerospace applications. It is being used in such applications as aircraft ducting systems, engine exhaust systems, thrust-reverser systems, turbine shroud rings, and heat-exchanger tubing in environmental control systems $[20,79,80]$.

\subsection{Ceramic and metal matrix composites}

CMCs and MMCs are a subgroup of composite materials, containing at least two phases with the dominating material being ceramic or metal correspondingly. As it is the common case with other composite materials, CMCs and MMCs show certain properties exceeding the ones of each constituent separately. Sometimes, their reinforcing phase consists of ceramic fibers embedded in a ceramic matrix [81]. In the last decade, intensive research was focused on the development of composite structures based 
on non-oxide compounds such as carbon, silicon carbide ( $\mathrm{SiC}$ ) and nitride $\left(\mathrm{Si}_{3} \mathrm{~N}_{4}\right)$, tungsten carbide (WC) etc. These compounds can be either a matrix or a reinforcing filler in the form of continuous or discrete fibers, whiskers, (combinations C/C, C/SiC, SiC/SiC) or micro- and nanoparticles. Such materials are often characterized by high strength, heat resistance, low density, and abrasion stability. These properties allow them to be used in aviation and space technology as high-temperature structural materials, for the elements of gas turbines, diesel engines, heat-exchangers, and in tribo-technology [82-86]. Composite materials of the type C/SiC and $\mathrm{SiC} /$ $\mathrm{SiC}$ are distinguished by low specific gravity, wear resistance, the possibility of the formation of these products of complex shape, in reducing conditions of operation, these composites retain high mechanical properties up to a temperature of $2000^{\circ} \mathrm{C}$ [87]. The most promising material at present is $\mathrm{SiC}$ and $\mathrm{SiC}$-based materials, which allow to obtain the specified combination of properties: high specific strength and rigidity; heat resistance; wear resistance; high thermal conductivity and heat-shielding properties; radiation strength [88]; etc.; thermal conductivity of 180 $200 \mathrm{~W} /(\mathrm{m} \cdot \mathrm{K})$ (as in $\mathrm{Al}$ ), in single crystals up to $470 \mathrm{~W} /$ $(\mathrm{m} \cdot \mathrm{K})$; working temperature - more than $1350^{\circ} \mathrm{C}$ (as in heatresistant steels); melting/decomposing point is $2830^{\circ} \mathrm{C}$; resistance in the oxidizing and reducing environment is higher than that of Ti [89]. PB-AM technologies demonstrate significant potential in manufacturing of composite materials both from the blended powders and pre-agglomerated powders where each grain already contains multiple materials sintered together $[28,38,39,90]$.

\subsection{High entropy alloys}

HEA belong to relatively novel class of metallic materials composed by at least five constituents in nearly equimolar concentrations with a thermodynamic preference to form one or more solid solutions instead of intermetallic compounds. The basic research in this novel topics of materials engineering and technology have been done by Yeh et al. [91], Wang et al. [92] and Zhang et al. [93]. Since configurational entropy of elements' mixing in disordered solid solution mixing is high (this is the reason for the term "high entropy alloys"), HEA's stability increases with temperature $[91,92]$. Due to this tendency, no undesirable intermetallics-induced embrittlement or precipitation over-hardening are expected in these materials. Solid solution strengthening obtained through complex mutual alloying, achieved through HEA synthesis, is expected to result in unique high mechanical properties, especially at elevated and high temperatures, namely: high temperature strength combined with creep resistance and high temperature fatigue resistance [93].

Presently, two main groups of HEAs can be mentioned: HEAs with face-center cubic (FCC) and HEAs with bodycentered cubic (BCC) crystal structure. To the first group belong alloys composed mainly of transition metals, while the second one contains mainly refractory metals-based alloys. The basic researches in BCC refractory metalsbased HEAs have been done by the group Senkov et al.
[94-100]. Taking into account the continuously growing demand in more temperature resistant materials for high temperature applications in aerospace industry [93-102], for example, in critical high-temperature parts with superior properties, like turbine blades [4], it becomes clear that refractory metals-based BCC HEAs are good candidates for these important applications [93-102]. Preliminary researches available in a scientific literature report on a principal possibility to synthesize BCC HEAs with can successfully serve as turbine blades at significantly higher temperatures that those available now through use of Ni-based superalloys [93-102].

The current processing of synthesizing HEAs is a vacuum arc melting [103-107]. Throughout applying this method, a vacuum atmosphere is used while heating the alloying materials up to a temperature higher permitting their complete melting. Then, liquid state mixing and mutual dissolution occurs. After completion of this process, the as-obtained homogeneous liquid is solidified and then the obtained solid is subjected to heat treatment. Usually, the last one is necessary for chemical and microstructural homogenization, which is critical for formation of the desired mechanical properties. The difference in melting points and vapor pressures of the alloying materials at high temperatures may be a quite problematic point of the mentioned process, especially in refractory metals bases HEAs, at which the melting points of the alloying materials are high and the castability of such complex liquid blend is insufficient to obtain a homogeneous material through the following solidifying. Furthermore, oxidation resistance of refractory metals is usually insufficient to obtain a product completely pure from oxidation, even under operating vacuum typical for high-temperature arc-melting furnaces. Taking into account the problematic aspects of the arcmelting under vacuum, it can be concluded that more appropriate HEA production route should be used for synthesizing refractory metals-based BCC HEAs.

One of the potential novel routes, which can be proposed for HEAs production, is PB-AM [22-29,32,39,51,90,108111]. The process permits a wide freedom to obtain almost all complicated part's geometry as desired. Obviously that this route could be used even for the parts made of the HEAs containing elements with low oxidation resistance and poor castability [34].

Traditional raw materials for PB-AM are pre-alloyed powders. Since the mutual alloying of the constituent elements composing such powders has been fulfilled throughout their production, their use is a convenient way to obtain homogeneous microstructures of as-printed products. On the other hand, if some unique raw material composition is required or some compositional fine-tuning of the product is required, the appropriate powders may unavailable or extremely expensive despite the availability of various methods for their manufacturing. Presently, insufficient availability of the pre-alloyed powders for new perspective materials is one of the constraints significantly slowing the progress of PB-AM, in general, and PB-AM of refractory based HEAs, in particular. Though the growing interest in the development of new materials for PB-AM is continuously increasing, today's state of the art regarding 
the trials for in situ alloying in PB-AM aiming at HEAs remains very restricted. Only few reported researches on this matter can be mentioned [22-29,32,39,51,90,108-111].

\subsection{Bulk metallic glass}

BMGs (amorphous metal, metallic glass) can be regarded as "one step further" compared to HEA, as these are metallic materials "without crystalline lattice". If in HEAs the main factor affecting microstructure formation is high configurational entropy of non-ordered solid solutions [9193], then BMGs formation is dictated by a crystallization delay caused by a suppressed diffusion resulted from kinetic factors like cooling rate and low mutual diffusivity of alloy's constituents [112-116]. It means that within the BMG's microstructure there is no long-range order $[114,116]$. Invented as more or less "scientific curiosity", these materials appeared to have a number of unique properties such as top hardness, strong abrasion and corrosion resistance even in the harshest of environments, superb fatigue properties and exceptional resilience unbeatable by any other known material [117]. Materials for modern ironbased BMG compositions manufacturing are not more expensive than the ones for high grade steels [30]. Ability of beam-based PB-AM of extremely fast highly localized melting and fast cooling make it extremely promising for BMG manufacturing [30,31]. Unfortunately relatively low glass transition point (heating above it and slowly cooling BMG returns it to crystalline state) commonly being within 450 to $580{ }^{\circ} \mathrm{C}$ strongly limits their application. In view of this most promising applications for aerospace and automotive industry are abrasive and corrosion resistive coatings and spring-like structures. And though BMG coatings can be applied using plasma spray technology, new modalities available from AM (see below on the composition-graded materials) seem to be quite promising for the future. Outstanding resilience together with exceptional fatigue stability promise to make BMGs a prime choice material for spring manufacturing. Simulations from material properties indicate that coil and leaf springs having same footprint and basic outline, and the same spring constant would be 5 to 10 times lighter if made in BMG, and will serve significantly longer as compared to the ones made from other materials. Thus design of new BMG materials and development of AM processes for their manufacturing is dramatically gaining pace.

\section{New modalities available with PB-AM}

Specifics of the PB-AM also allows for additional advantages resulting from the modalities available with AM but not with other technologies. Rather well known for PB-AM capacity for manufacturing thin-walled, honeycomb, cellular and other lightweight structures together with other sections of a component in the same manufacturing process open a whole lane of opportunities for the automotive and aerospace applications. Fast localized melting and cooling intrinsic to PB-AM was already mentioned above related to the manufacturing of HEA and BMGs. Other modalities like the ability of manufacturing so-called composition- and functionallygraded materials, and microstructure (and thus- property) steering in 3D also available with $\mathrm{PB}-\mathrm{AM}$ are among additional unique options becoming available.

\subsection{Lightweight structures}

One of the common weight reduction possibilities beyond the choice of lightweight alloy is incorporating openwork sections into the components. Due to the shape flexibility of PB-AM, lightweight sections can be easily made together with the solid sections of a component in a single manufacturing process. Typical examples of such components are thin-walled ones (like honeycomb structures [118]) as well as lattices (cellular) structures of different design [119,120]. Another feature significantly differing $\mathrm{PB}-\mathrm{AM}$ manufacturing is that there is no need to make lightweight structures fully repetitive and symmetric. This opens the possibility to vary the properties of the lightweight structures (apparent density and unit cell dimensions) by design, stepwise or gradually [121]. More complex designs, with the anisotropic unite cell lattices providing anisotropy of the structure mechanical properties, are also possible. Though manufacturing of such lightweight components is entirely possible, their design is still a complex undertaking due to the lack of powerful enough software tools for automated generation of, for example, high complexity lattice structures.

\subsection{Compositionally- and functionally-graded materials}

Another unique possibility is provided by the PB-AM systems capable of advanced powder feeding and localized beam energy deposition variation. For example, changing the composition of the powder in consecutive layers (changing materials, changing blending ratio of materials) already allows for manufacturing compositionally- and functionally- graded materials $[39,121]$. So far, the early attempts are made with only slight modifications of the commercial PB-AM systems, which limit them to only planar structure manufacturing. But engineering community is already looking for the powder delivery solutions allowing for the material changes within a single layer. One of the definite advantages of the compositionally- graded materials, where the mixing ratios of two different powdered materials is gradually changes layer from layer is in the enhanced stability of such structure to the thermal and mechanical load cycling. In the typical example of the hard coating on the softer metallic material thin boundary layer between two concentrates high stress during loading or changing temperature conditions. With gradual change in the material composition levels of such stress is considerably lower.

Because the microstructure of the PB-AM manufactured materials depends on the thermal conditions during melting-solidification process it is possible to vary the material microstructure and thus material properties locally, within essentially a single layer, varying the energy deposited by the beam [39]. It was also shown that such beam energy deposition steering combined with feeding blend of two powders allows to locally change the 
composition of the component going from composite to mixed alloy $[28,39]$. This allows the structures with hard abrasive resistant outer surfaces and reinforcement elements inside surrounded by amore ductile "core".

This expanded methodology can be already called true 4D-printing, where flexibility comes in three of spatial dimensions, and material composition as a fourth dimension. Such space- and material flexibility on one manufacturing process will definitely find valuable application in different technological areas including automotive and aerospace industry.

\section{Future trends and challenges}

Taking into account the growing demand in novel highperformance materials with unique combination of mechanical, physical and chemical properties, certain main future trends in PB-AM can be envisaged.

Firstly, the industrial acceptance of PB-AM will continue to grow across the industries, including few sectors most benefiting of its development-aerospace, automotive and biomedical ones. The growth of the PBAM applications using materials already traditional for aerospace and automotive industry like Ti-based, Febased, Al-based alloys will continue mainly around the possibilities of manufacturing components with complex shapes, incorporated lightweight structures, cooling channels. Here the benefits could be expected primarily from weight and cost savings per manufactured component. Additional benefit could be expected in reducing the spare part handling costs, as in many cases storing large numbers of different items can be substituted by manufacturing parts on demand from saved computer files.

Secondly, the trend towards using unique capacity of PBAM methods of manufacturing components from materials with highly attractive properties will continue to grow. This trend is already well pronounced, and it starts with the PBAM manufacturing with materials that are hard or impossible to process using other manufacturing methods, either due to the demanded component shape complexity, or due to the resulting material properties. This trend will see further development of PB-AM manufacturing and of Nisuperalloys and their wider acceptance in automotive and aerospace applications, as well as introduction of industrial processes for HEA and BMG.

Thirdly, the trend of incorporating PB-AM manufacturing into unified automated and robotic processing lines together with the post-machining and postprocessing will continue. Many of such systems are already in development, and were already shown to provide better integration of the PB-AM manufactured components into existing industrial process lines.

One of the developing trends promising large benefits for aerospace and automotive industries is PB-AM manufacturing of components from materials with controlled properties throughout their volume by precisely controlling the material composition and microstructure, adding 4th dimension to 3D-printing. Possibilities of powder blends with varying composition in BJP and beam-based PB-AM, steering the microstructure of the components inside the component by adjusting the beam energy deposition selectively in each layer with beam-based technologies were already successfully demonstrated.

There are certain challenges preventing PB-AM to gain wider acceptance in the industrial manufacturing. Few of them are related to the integration of PB-AM into the existing, well-established technological chains. These challenges are ranging from differencing in acquiring raw materials, to the need of introducing changes into design philosophy (design for AM is free of some restrictions commonly "hard-wired" into traditional industrial design, but new methods introduce few of their own, specific restrictions), establishing new ways of quality control and standardization, developing different component postprocessing, integrating of additively manufactured components into existing systems, developing new approaches to life cycle analysis, and different ways of cost and resource management, etc. It is a serious undertaking involving equipment, work force, logistics- essentially all facets of the industrial process. In a way, a new "child" is already conceived within traditional industry and even born, but it takes careful efforts before it matures.

One can outline following specific directions in nearest future of PB-AM aiming at better realizing its potential: - adaptation and adjustment of existing PB-AM techniques towards;

- production of defectless lightweight parts with high specific strength (beam-based processing);

- production of high-performance alloys with advanced microstructure (BJP), including Ni-based superalloys (powder bed beam-based processing with possible combination with in situ alloying);

- BMGs (powder bed beam-based processing, powder bed BJP processing);

- HEAs (beam-based processing with possible combination with in situ alloying);

- ceramic and non-metal-based composite materials (powder-bed BJP processing);

- metal-based composite materials (beam-based PB-AM and BJP processing);

- compositionally and functionally graded materials (PBAM both beam-based and BJP processing);

- materials research and development of in situ alloying throughout beam-based PB-AM (EBM and SLM), which can potentially allow using elemental powder and complex powder blends instead of fully pre-alloyed powders as raw materials for production parts made of multi-component metallic alloys;

- material research in the field of a post processing aimed to eliminate residual porosity after beam-based processing for metallic materials, as well as after BJP processing for ceramic, composite and functionally graded materials and BMGs;

- research in optimization of the existing PB-AM production routes aiming at faster and more effective manufacturing; 
- industrialization of the approaches to functional optimization of the component design adding functionality criteria (loads, stresses, thermal properties etc.) to shape and weight one within design flow;

- developing common metrology and quality control procedures into the PB-AM manufacturing flow and products standardization aimed to fit the existing aerospace specifications.

\section{Summary}

The main common development trends of state-of-the-art additive manufacturing production routes application in aerospace can be extracted from the current review and then summarized as follows:

- extending range of the precursor materials, namely: metallic alloys (including HEAs and BMGs), metal and ceramic matrix composites and composite-like materials, lightweight structures and compositionally and functionally graded materials (CGMs and FGMs) used for aerospace applications;

- increasing rate of application trials of various PB-AM techniques for aerospace;

- focus on additive manufacturing of critical aerospace components;

- standardization of regulations of additive manufacturing for aerospace.

\section{Conflict of interests}

The authors declare that they have no conflicts of interest in relation to this article.

\section{References}

1. V.V. Popov, G. Muller-Kamskii, A. Kovalevsky, G. Dzhenzhera, E. Strokin, A. Kolomiets, J. Ramon, Design and 3D-printing of titanium bone implants: Brief review of approach and clinical cases, Biomed. Eng. Lett. 8 (2018) 337-344

2. V. Popov Jr., G. Muller-Kamskii, A. Katz-Demyanetz, A. Kovalevsky, S. Usov, D. Trofimcow, G. Dzhenzhera, A. Koptyug, Additive manufacturing to veterinary practice: Recovery of bony defects after the osteosarcoma resection in canines, Biomed. Eng. Lett. (2019), doi: 10.1007/s13534018-00092-7

3. K. Satish Prakash, T. Nancharaih, V.V. Subba Rao, Additive manufacturing techniques in manufacturing-An overview, Mater. Today: Proc. Part 15 (2018) 3873-3882

4. T.D. Ngo, A. Kashani, G. Imbalzano, K.T. Nguyen, D. Hui, Additive manufacturing (3D printing): A review of materials, methods, applications and challenges, Compos. Part B: Eng. 143 (2018) 172-196

5. N. Li, S. Huang, G. Zhang, R. Qin, W. Liu, H. Xiong, G. Shi, J. Blackburn, Progress in additive manufacturing on new materials: A review, J. Mater. Sci. Technol. 35 (2019) 242-269
6. S. Lathabai, Chapter 2-Additive manufacturing of aluminium-based alloys and composites, in: R.N. Lumley (Ed), Woodhead Publishing Series in Metals and Surface Engineering, Fundamentals of Aluminium Metallurgy, Woodhead Publishing, 2018, pp. 47-92

7. V.V. Popov, A. Katz-Demyanetz, A. Garkun, M. Bamberger, The effect of powder recycling on the mechanical properties and microstructure of electron beam melted $\mathrm{Ti}-$ 6Al-4V specimens, Addit. Manuf. 22 (2018) 834-843

8. N. Pushilina, M. Syrtanov, E. Kashkarov, T. Murashkina, V. Kudiiarov, R. Laptev, A. Lider, A. Koptyug, Influence of manufacturing parameters on microstructure and hydrogen sorption behavior of electron beam melted titanium Ti-6Al4V alloy, Materials 11 (2018) 763

9. H.K. Rafi, N.V. Karthik, H. Gong, T.L. Starr, B.E. Stucker, Microstructures and mechanical properties of Ti6Al4V parts fabricated by selective laser melting and electron beam melting, J. Mater. Eng. Perform. 22 (2013) 3872-3883

10. V. Popov, A. Katz-Demyanetz, M. Bamberger, Heat transfer and phase formation through EBM 3D-Printing of Ti-6Al-4V cylindrical parts, Defect Diffus. Forum 383 (2018) 190-195

11. A. Adeyemi, E.T. Akinlabi, R.M. Mahamood, Powder bed based laser additive manufacturing process of stainless steel: A review, Mater. Today: Proc. Part 35 (2018) 18510-18517

12. L.E. Rännar, A. Koptyug, J. Olsén, K. Saeidi, Z. Shen, Hierarchical structures of stainless steel $316 \mathrm{~L}$ manufactured by electron beam melting, Addit. Manuf. 17 (2017) 106-112

13. A. Bohlen, H. Freiße, M. Hunkel, F. Vollertsen, Additive manufacturing of tool steel by laser metal deposition, Proced. CIRP 74 (2018) 192-195

14. D. Wang, C. Yu, X. Zhou, J. Ma, W. Liu, Z. Shen, Dense pure tungsten fabricated by selective laser melting, Appl. Sci. 7 (2017) 430

15. V. Livescu, C.M. Knapp, G.T. Gray, R.M. Martinez, B.M. Morrow, B.G. Ndefru, Additively manufactured tantalum microstructures, Materialia 1 (2018) 15-24

16. J.A. Gonzalez, J. Mireles, S.W. Stafford, M.A. Perez, C.A. Terrazas, R.B. Wicker, Characterization of Inconel 625 fabricated using powder-bed-based additive manufacturing technologies, J. Mater. Process. Technol. 264 (2019) 200-210

17. P. Nandwana, A.M. Elliott, D. Siddel, A. Merriman, W.H. Peter, S.S. Babu, Powder bed binder jet 3D printing of Inconel 718: Densification, microstructural evolution and challenges, Curr. Opin. Solid State Mater. Sci. 12 (2017) 1-12

18. M. Turker, D. Godlinski, F. Petzoldt, Effect of production parameters on the properties of Ni 718 superalloy by threedimensional printing, Mater. Charact. 59 (2008) 1728-1735

19. N. Peeyush, M. Elliott, D. Siddel, A. Merriman, W.H. Peter, Powder bed binder jet 3D printing of Inconel 718: Densification, microstructural evolution and challenges, Curr. Opin. Solid State Mater. Sci. 21 (2017) 207-218

20. A. Mostafaei, E.L. Stevens, E.T. Hughes, S.D. Biery, C. Hilla, M. Chmielus, Powder bed binder jet printed alloy 625 : Densification, microstructure and mechanical properties, J. Mater. Des. 108 (2016) 126-135

21. Z. Wang, K. Guan, M. Gao, X. Li, X. Chen, X. Zeng, The microstructure and mechanical properties of depositedIN718 by selective laser melting, J. Alloy. Compd. 513 (2012) 518-523 
22. V. Ocelik, N. Janssen, S.N. Smith, J.Th.M. De Hosson, Additive manufacturing of high-entropy alloys by laser processing, JOM 68 (2016) 1810-1818

23. X. Li, Additive manufacturing of advanced multi-component alloys: Bulk metallic glasses and high entropy alloys, Adv. Eng. Mater. 20 (2018) 1700874

24. Q. Chao, J. Joseph, P. Hodgson, D. Fabijanic, Direct laser manufactured high entropy alloys, IWHEM-2017 Digest book, School of Engineering Sciences and Technology, University of Hyderabad, Hyderabad, India, 2017, p. 24

25. R. Zhou, Y. Liu, C. Zhou, S. Li, W. Wu, M. Song, B. Liu, X. Liang, P.K. Liaw, Microstructures and mechanical properties of C-containing $\mathrm{FeCoCrNi}$ high-entropy alloy fabricated by selective laser melting, Intermetallics 94 (2018) 165-171

26. Z.G. Zhu, Q.B. Nguyen, F.L. Ng, X.H. An, X.Z. Liao, P.K. Liaw, S.M.L. Nai, J. Wei, Hierarchical microstructure and strengthening mechanisms of a CoCrFeNiMn high entropy alloy additively manufactured by selective laser melting, Scr. Mater. 154 (2018) 20-24

27. Y. Brif, M. Thomas, I. Todd, The use of high-entropy alloys in additive manufacturing, Scr. Mater. 99 (2015) 93-96

28. V.V. Popov, A. Katz-Demyanetz, A. Koptyug, M. Bamberger, Selective electron beam melting of $\mathrm{Al} 0.5 \mathrm{Cr}-$ MoNbTa0.5 high entropy alloys using elemental powder blend, Heliyon 5 (2019) e01188

29. K. Kuwabara, H. Shiratori, T. Fujieda, K. Yamanaka, Y. Koizumi, A. Chiba, Mechanical and corrosion properties of $\mathrm{AlCoCrFeNi}$ high-entropy alloy fabricated with selective electron beam melting, Addit. Manuf. 23 (2018) 264-271

30. A. Koptyug, L.-E. Rannar, M. Backstorm, R. Langlet, Bulk metallic glass manufacturing using electron beam melting, Proceedings from Additive Manufacturing \& 3D Printing, Nottingham, UK, 2013

31. E. Williams, N. Lavery, Laser processing of bulk metallic glass: A review, J. Mater. Process. Technol. 247 (2017) 73-91

32. Arcam EBM, A GE additive company, Available from http://www.arcam.com/

33. A. Koptioug, L.E. Rännar, M. Bäckström, Z.J. Shen, New metallurgy of additive manufacturing in metal: Experiences from the material and process development with electron beam melting technology (EBM), Mater. Sci. Forum. 879 (2016) 996-1001

34. X. Gong, T. Anderson, K. Chou, Review on powder-based electron beam additive manufacturing technology, Manuf. Rev. 1 (2014) 2

35. V.M. Dovbysh, P.V. Zabednov, M.A. Zlenko, Additivnye tekhnologii i izdeliya iz metalla [Additive technologies and metal products], Russia "NAMI" (in Russian), Caster Lib. 9 (2014) 14-71

36. X. Zhao, D. Gu, C. Ma, L. Xi, H. Zhang, Microstructure characteristics and its formation mechanism of selective laser melting $\mathrm{SiC}$ reinforced Al-based composites, Vacuum 160 (2019) 189-196

37. O.D. Neikov, Chapter 13-Powders for additive manufacturing processing, in: O. Neikov, S. Naboychenko, N.V. Yefimov (Eds), Handbook of non-ferrous metal powders (2nd Edition), Elsevier, Amsterdam, Netherlands, 2019, pp. 373-399

38. V. Popov, A. Koptyug, I. Radulov, F. Maccari, G. Muller, Prospects of additive manufacturing of rare-earth and nonrare-earth permanent magnets, Proced. Manuf. 21 (2018) $100-108$
39. A. Koptyug, M. Bäckström, C. Botero, V. Popov, E. Chudinova, Developing new materials for electron beam melting: Experiences and challenges, Mater. Sci. Forum 941 (2018) 2190-2195

40. A. Koptyug, L.-E. Rännar, C. Botero, M. Bäckström, V. Popov, Blended powders can be successfully used in electron beam melting yielding unique material compositions, EuroPM2018 Proceedings, European Powder Metallurgy Association (EPMA), Bilbao, Spain, 2018

41. J. Pegues, M.l Roach, R.S. Williamson, N. Shamsaei, Surface roughness effects on the fatigue strength of additively manufactured Ti-6Al-4V, Int. J. Fatigue 116 (2018) 543-552

42. A.M. Rausch, M. Markl, C. Körner, Predictive simulation of process windows for powder bed fusion additive manufacturing: Influence of the powder size distribution, Comput. Math. Appl. (2018), doi: 10.1016/j.camwa.2018.06.029

43. V. Popov, A. Katz-Demyanetz, A. Garkun, G. Muller, E. Strokin, H. Rosenson, Effect of hot isostatic pressure treatment on the electron-beam melted Ti- $6 \mathrm{Al}-4 \mathrm{~V}$ specimens, Proced. Manuf. 21 (2018) 125-132

44. P. Tyagi, T. Goulet, C. Riso, R. Stephenson, N. Chuenprateep, J. Schlitzer, C. Benton, F. Garcia-Moreno, Reducing the roughness of internal surface of an additive manufacturing produced 316 steel component by chempolishing and electropolishing, Addit. Manuf. 25 (2019) $32-38$

45. I.Y. Grubova, M.A. Surmeneva, A.A. Ivanova, K. Kravchuk, O. Prymak, M. Epple, V. Buck, R.A. Surmenev, The effect of patterned titanium substrates on the properties of silver-doped hydroxyapatite coatings, Surf. Coat. Technol. 276 (2015) 595-601

46. M. Peszka, Hirtenberger hirtisation technology provides speed and automatic post-processing (in Polish), 2018, Available from https://www.centrumdruku3d.xyz/arty $\mathrm{kul} /$ technologia-hirtisation-hirtenberger-zapewnia-szyb kosc-i-automatyzacje-post-processingu/2114

47. S.A. Khairallah, A.T. Anderson, A. Rubenchik, W.E. King, Laser powder-bed fusion additive manufacturing: Physics of complex melt flow and formation mechanisms of pores, spatter, and denudation zones, Acta Mater. 108 (2016) 36-45

48. K. Lin, L. Yuan, D. Gu, Influence of laser parameters and complex structural features on the bio-inspired complex thin-wall structures fabricated by selective laser melting, J. Mater. Process. Technol. 267 (2019) 34-43

49. J. Zhang, B. Song, Q. Wei, D. Bourell, Y. Shi, A review of selective laser melting of aluminum alloys: Processing, microstructure, property and developing trends, J. Mater. Sci. Technol. 35 (2019) 270-284

50. L. Mugwagwa, D. Dimitrov, S. Matope, I. Yadroitsev, Influence of process parameters on residual stress related distortions in selective laser melting, Proced. Manuf. 21 (2018) 92-99

51. R. Dehoff, M. Kirka, W.J. Sames, H. Bilheux, A. Tremsin, L. Lowe, S. Babu, Site specific control of crystallographic grain orientation through electron beam additive manufacturing, Mater. Sci. Technol. 31 (2015) 931-938

52. Y. Zhong, L.-E. Rännar, S. Wikman, A. Koptyug, L. Liu, D. Cui, Z. Shen, Additive manufacturing of ITER first wall panel parts by two approaches: Selective laser melting and electron beam melting, Fusion Eng. Des. 116 (2017) $24-33$ 
53. Q.B. Nguyen, Z. Zhu, B.W. Chua, W. Zhou, J. Wei, S.M.L. Nai, Development of WC-Inconel composites using selective laser melting, Arch. Civ. Mech. Eng. 18 (2018) 1410-1420

54. I. Gibson, D. Rosen, B. Stucker, Binder jetting, in: Additive Manufacturing Technologies, Springer, New York, USA, 2015, pp. 205-218

55. M.P. Paranthaman, C.S. Shafer, A.M. Elliott, D.H. Siddel, M.A. McGuire, R.M. Springfield, J. Martin, R. Fredette, J. Ormerod, Binder jetting: A novel NdFeB bonded magnet fabrication process, JOM 68 (2016) 1978-1982

56. A. Mostafaei, P. Rodriguez, I. Nettleship, M. Chmielus, Effect of powder size distribution on densification and microstructural evolution of binder-jet 3D-printed alloy 625 , Mater. Des. 162 (2019) 375-383

57. P. Kunchala, K. Kappagantula, 3D printing high density ceramics using binder jetting with nanoparticle densifiers, Mater. Des. 155 (2018) 443-450

58. P. Enrique, Y. Mahmoodkhani, E. Marzbanrad, E. Toyserkani, N. Zhou, In situ formation of metal matrix composites using binder jet additive manufacturing (3D printing), Mater. Lett. 232 (2018) 179-182

59. A. Mostafaei, S. Vardhan, R. Neelapu, C. Kisailus, L. Nath, T. Jacobs, M. Chmielus, Characterizing surface finish and fatigue behavior in binder-jet 3D-printed nickel-based superalloy 625, Addit. Manuf. 24 (2018) 200-209

60. N. Larianovsky, V.V. Popov Jr., A. Katz-Demyanetz, A. Fleisher, D.E. Meyers, S. Chaudhuri, Production of Al metal matrix composites reinforced with carbon nanotubes by twostage melt-based HPDC-CE Method, ASME, J. Eng. Mater. Technol. 141 (2018) 011002

61. M. Peters, J. Kumpfert, C.H. Ward, C. Leyens, Titanium alloys for aerospace applications, Adv. Eng. Mater. 5 (2003) 419-427

62. J. Hu, K. Zhang, Q. Yang, H. Cheng, S. Liu, Y. Yang, Fretting behaviors of interface between CFRP and coated titanium alloy in composite interference-fit joints under service condition, Mater. Des. 134 (2017) 91-102

63. V.V. Popov Jr., A. Katz-Demyanetz, A. Kovalevsky, R. Biletskiy, E. Strokin, A. Garkun, M. Bamberger, Effect of the hatching strategies on mechanical properties and microstructure of SEBM manufactured $\mathrm{Ti}-6 \mathrm{Al}-4 \mathrm{~V}$ specimens, Lett. Mater. 8 (2018) 468-472

64. T.M. Angeliu, J.T. Ward, J.K. Witter, Assessing the effects of radiation damage on Ni-base alloys for the prometheus space reactor system, J. Nucl. Mater. 366 (2007) 223-237

65. Z. Huda, P. Edi, Materials selection in design of structures and engines of supersonic aircrafts: A review, Mater. Des. 46 (2013) 552-560

66. M. Perruta, P. Carona, M. Thomasa, A. Couret, High temperature materials for aerospace applications: Ni-based superalloys and $\gamma$-TiAl alloys, C.R. Phys. 19 (2018) 657-671

67. Y.C. Lin, D.X. Wen, J. Deng, G. Liu, J. Chen, Constitutive models for high-temperature flow behaviors of a Ni-based superalloy, Mater. Des. 59 (2014) 115-123

68. B.C. Behera, H. Alemayehu, S. Ghosh, P.V. Rao, A comparative study of recent lubri-coolant strategies for turning of Ni-based superalloy, J. Manuf. Process. 30 (2017) $541-552$

69. Y.C. Lin, F.Q. Nong, X.M. Chen, D.D. Chen, Microstructural evolution and constitutive models to predict hot deformation behaviors of a nickel-based superalloy, Vacuum 137 (2017) 104-114
70. Y. Behnamian et al., A comparative study on corrosion behavior of stainless steel and nickel-based superalloys in ultra-high temperature supercritical water at $800^{\circ} \mathrm{C}$, Corros. Sci. 106 (2016) 188-207

71. L. Garcia-Fresnillo, A. Chyrkin, C. Bo, J. Barnikel, F. Schmitz, W.J. Quadakkers, Oxidation behaviour and microstructural stability of alloy 625 during long-term exposure in steam, J. Mater. Sci. 49 (2014) 6127-6142

72. T.M. Pollock, N. Rene, Nickel-based superalloys for advanced turbine engines: Chemistry, microstructure, and properties, J. Propuls. Power 22 (2006) 361-374

73. R.C. Reed, The superalloys: Fundamentals and applications, Cambridge University Press, Cambridge, UK, 2006

74. Special Metals Corporation, Available from http://www. specialmetals.com/

75. C.M. Kuo, Y.T. Yang, H.Y. Bor, C.N. Wei, C.C. Tai, Aging effects on the microstructure and creep behavior of Inconel 718 superalloy, Mater. Sci. Eng. A 510-511 (2009) 289-294

76. P.K. Pedro, Ö. Utkudeniz, C. Jessica, M.C. José, G.M. Martha, High-temperature deformation of delta-processed Inconel 718, J. Mater. Process. Tech. 255 (2018) 204-211

77. S. Kumar, G.S. Rao, K. Chattopadhyay, G.S. Mahobia, N. C.S. Srinivas, V. Singh, Effect of surface nanostructure on tensile behavior of superalloy IN718, Mater. Des. 62 (2014) $76-82$

78. M.D. Mathew, P. Parameswaran, K. Bhanu, S. Rao, Microstructural changes in alloy 625 during high temperature creep, Mater. Charact. 59 (2008) 508-513

79. Y. Behnamian, A. Mostafaei, A. Kohandehghan, B.S. Amirkhiz, D. Serate, Y. Sun, S. Liu, E. Aghaie, Y. Zeng, M. Chmielus, W. Zheng, D. Guzonas, W. Chen, J. Li Luo, A comparative study of oxide scales grown on stainless steel and nickel-based superalloys in ultra-high temperature supercritical water at $800^{\circ} \mathrm{C}$, Corros. Sci. 106 (2016) 188-207

80. T.M. Pollock, S. Tin, Nickel-based superalloys for advanced turbine engines: Chemistry, microstructure, and properties, J. Propuls. Power 22 (2006) 361-374

81. F. Christin, CMC materials for space and aeronautical applications. Ceramic matrix composites, Wiley-VCH Verlag GmbH \& Co. KGaA, Weinheim, Germany, 2008, pp. 327-351

82. A. Sommers, Q. Wang, X. Han, C. T'Joen, Y. Park, A. Jacobi, Ceramics and ceramic matrix composites for heat exchangers in advanced thermal systems - A review, Appl. Therm. Eng. 30 (2010) 1277-1291

83. I. Ahmad, B. Yazdani, Y. Zhu, Recent advances on carbon nanotubes and graphene reinforced ceramics nanocomposites, Nanomaterials 5 (2015) 90-114

84. S. Fan, C. Yang, L. He, Y. Du, W. Krenkel, P. Greil, N. Travitzky, Progress of ceramic matrix composites brake materials for aircraft application, Rev. Adv. Mater. Sci. 44 (2016) 313-325

85. L.S. Walker, V.R. Marotto, M.A. Rafiee, N. Koratkar, E.L. Corral, Toughening in graphene ceramic composites, ACS Nano. 5 (2011) 3182-3190

86. J. Liu, H. Yan, K. Jiang, Mechanical properties of graphene platelet-reinforced alumina ceramic composites, Ceram. Int. 39 (2013) 6215-6221

87. B. Heidenreich, C/SiC and C/C-SiC composites, ceramic matrix composites, John Wiley \& Sons Inc., Hoboken, NJ, USA, 2014, pp. 147-216 
88. B.L. Wing, J.W. Halloran, Microstress in the matrix of a melt-infiltrated $\mathrm{SiC} / \mathrm{SiC}$ ceramic matrix composite, J. Am. Ceram. Soc. 38 (2017) 42-49

89. N. Al Nasiri, N. Patra, N. Ni, D.D. Jayaseelan, W.E. Lee, Oxidation behaviour of $\mathrm{SiC} / \mathrm{SiC}$ ceramic matrix composites in air, J. Eur. Ceram. Soc. 36 (2016) 3293-3302

90. C. Haase, F. Tang, M.B. Wilms, A. Weisheit, B. Hallstedt, Combining thermodynamic modeling and 3D printing of elemental powder blends for high-throughput investigation of high-entropy alloys - Towards rapid alloy screening and design, Mater. Sci. Eng. A 688 (2017) 180-189

91. J.W. Yeh, S.K. Chen, S.J. Lin, J.Y. Gan, T.S. Chin, T.T. Shun, C.H. Tsau, S.Y. Chang, Nanostructured high-entropy alloys with multiple principal elements: Novel alloy design concepts and outcomes, Adv. Eng. Mater. 6 (2004) 299-303

92. Y.P. Wang, B.S. Li, H.Z. Fu, Solid solution or intermetallics in a high-entropy alloy, Adv. Eng. Mater. 11 (2009) 641-644

93. Y. Zhang, X. Yang, P.K. Liaw, Alloy design and properties optimization of high-entropy alloys, JOM 64 (2012) 830-838

94. O.N. Senkov, G.B. Wilks, J.M. Scott, D.B. Miracle, Mechanical properties of Nb25Mo25Ta25W25 and V20Nb20Mo20Ta20W20 refractory high entropy alloys, Intermetallics 19 (2011) 698-706

95. O.N. Senkov, J.M. Scott, S.V. Senkova, D.B. Miracle, C.F. Woodward, Microstructure and room temperature properties of a high-entropy TaNbHfZrTi alloy, J. Alloy. Compd. 509 (2011) 6043-6048

96. O.N. Senkov, S.V. Senkova, C.F. Woodward, D.B. Miracle, Low-density, refractory multi-principal element alloys of the Cr-Nb-Ti-V-Zr system: Microstructure and phase analysis, Acta Mater. 61 (2013) 1545-1557

97. O.N. Senkov, C.F. Woodward, Microstructure and properties of a refractory NbCrMo0.5Ta0.5TiZr alloy, Mater. Sci. Eng. A 529 (2011) 311-320

98. O.N. Senkov, J.M. Scott, S.V. Senkova, F. Meisenkothen, D. B. Miracle, C.F. Woodward, Microstructure and elevated temperature properties of a refractory TaNbHfZrTi alloy, J. Mater. Sci. 47 (2012) 4062-4074

99. O.N. Senkov, J.M. Scott, S.V. Senkova, D.B. Miracle, C.F. Woodward, Microstructure and room temperature properties of a high-entropy TaNbHfZrTi alloy, J. Alloy. Compd. 509 (2011) 6043-6048

100. O.N. Senkov, S.L. Semiatin, Microstructure and properties of a refractory high-entropy alloy after cold working, J. Alloy. Compd. 649 (2015) 1110-1123

101. P.K. Liaw, F. Zhang, National Energy Technology Laboratory Research: Experimental and computational investigation of high-entropy alloys for elevated high-temperature applications, Grant presentation FE-0008855, University of Tennessee at Knoxville, USA, 2016

102. M.A. Hemphill, Fatigue behavior of high entropy alloys, Master's Thesis, University of Tennessee, Knoxville, 2012

103. O.N. Senkov, J.M. Scott, S.V. Senkova, F. Meisenkothen, D. B. Miracle, C.F. Woodward, Microstructure and elevated temperature properties of a refractory TaNbHfZrTi alloy, J. Mater. Sci. 47 (2012) 4062-4074

104. O.N. Senkov, J.M. Scott, S.V. Senkova, D.B. Miracle, C.F. Woodward, Microstructure and room temperature properties of a high-entropy TaNbHfZrTi alloy, J. Alloy. Compd. 509 (2011) 6043-6048
105. N. Larianovsky, A. Katz-Demyanetz, E. Eshed, M. Regev, Microstructure, tensile and creep properties of Ta20Nb20Hf20Zr20Ti20 high entropy alloy, Materials 10 (2017) 883

106. E. Eshed, N. Larianovsky, A. Kovalevsky, V. Popov Jr., I. Gorbachev, V. Popov, A. Katz-Demyanetz, Microstructural evolution and phase formation in 2nd-generation refractorybased high entropy alloys, Materials 11 (2018) 75

107. E. Eshed, N. Larianovsky, A. Kovalevsky, A. KatzDemyanetz, Effect of Zr on the microstructure of secondand third-generation BCC HEAs, JOM 71 (2019) 673-682

108. S.-H. Sun, Y. Koizumi, S. Kurosu, Y.-P. Li, H. Matsumoto, A. Chiba, Build direction dependence of microstructure and high-temperature tensile property of $\mathrm{Co}-\mathrm{Cr}-\mathrm{Mo}$ alloy fabricated by electron beam melting, Acta Mater. 64 (2014) 154-168

109. T. Fujieda, H. Shiratori, K. Kuwabara, T. Kato, K. Yamanaka, Y. Koizumi, A. Chiba, First demonstration of promising selective electron beam melting method for utilizing high-entropy alloys as engineering materials, Mater. Lett. 159 (2015) 12-15

110. T. Fujieda, H. Shiratori, K. Kuwabara, M. Hirota, T. Kato, K. Yamanaka, Y. Koizumi, A. Chiba, S. Watanabe, CoCrFeNiTi-based high-entropy alloy with superior tensile strength and corrosion resistance achieved by a combination of additive manufacturing using selective electron beam melting and solution treatment, Mater. Lett. 189 (2017) 148-151

111. H. Shiratori, T. Fujieda, K. Yamanaka, Y. Koizumi, K. Kuwabara, T. Kato, A. Chiba, Relationship between the microstructure and mechanical properties of an equiatomic $\mathrm{AlCoCrFeNi}$ high-entropy alloy fabricated by selective electron beam melting, Mater. Sci. Eng.: A 656 (2016) 39-46

112. H.S. Chen, Thermodynamic considerations on the formation and stability of metallic glasses, Acta Met. 22 (1974) 15051511

113. M. Telford, The case of bulk metallic glasses, Mater. Today 7 (2004) 36-43

114. W.H. Wang, C. Dong, C.H. Shek, Bulk metallic glasses, Mater. Sci. Eng.: R 44 (2004) 45-89

115. A. Inoue, Stabilization of metallic supercooled liquid and bulk amorphous alloys, Acta Mater. 48 (2000) 279-306

116. J. Cheney, K. Vecchio, Prediction of glass-forming compositions using liquidus temperature calculations, Mater. Sci. Eng. A 471 (2007) 135-143

117. M.M. Trexler, N.N. Thadhami, Mechanical properties of bulk metallic glasses, Progress Mater. Sci. 55 (2010) 759-839

118. N. Chantarapanich, A. Laohaprapanon, S. Wisutmethangoon, P. Jiamwatthanachai, P. Chalermkarnnon, S. Sucharitpwatskul, P. Puttawibul, K. Sitthiseripratip, Fabrication of three-dimensional honeycomb structure for aeronautical applications using selective laser melting: A preliminary investigation, Rapid Prototyp. J. 20 (2014) 551-558

119. D. Khrapov, M. Surmeneva, A. Koptioug, S. Evsevleev, F. Léonard, G. Bruno, R. Surmenev, X-ray computed tomography of multiple-layered scaffolds with controlled gradient cell lattice structures fabricated via additive manufacturing, J. Phys. Conf. Ser. 1145 (2019) 012044 
120. A. Panesar, M. Abdi, D. Hickman, I. Ashcroft, Strategies for functionally graded lattice structures derived using topology optimisation for additive manufacturing, Addit. Manuf. 19 (2018) 81-94
121. Y. Wang, L. Zhang, S. Daynes, H. Zhang, S. Feih, M. Yu Wang, Design of graded lattice structure with optimized mesostructures for additive manufacturing, Mater. Des. 142 (2018) 114-123

Cite this article as: Alexander Katz-Demyanetz, Vladimir V. Popov Jr., Aleksey Kovalevsky, Daniel Safranchik, Andrey Koptyug, Powder-bed additive manufacturing for aerospace application: Techniques, metallic and metal/ceramic composite materials and trends, Manufacturing Rev. 6, 5 (2019) 